\title{
Correction: High-mobility group box 1 induces endoplasmic reticulum stress and activates hepatic stellate cells
}

\author{
Qin $\mathrm{He}^{1} \cdot \mathrm{Yu} \mathrm{Fu}{ }^{2} \cdot$ Xiangming $\mathrm{Ding}^{1} \cdot$ Dongxiao $\mathrm{Li}^{1} \cdot \mathrm{Zi} \mathrm{Wang}^{1} \cdot$ Dean Tian ${ }^{1} \cdot$ Wei Yan ${ }^{1}$
}

Published online: 31 October 2018

(c) United States \& Canadian Academy of Pathology 2018

Correction to: Laboratory Investigation; https://doi.org/10. 1038/s41374-018-0085-9; Article published online 29 June 2018

Following publication of the original article, the authors noticed a few errors in Figs. 1-3:

1. In Fig. 1c2, incorrect molecular weight and name of lamin was provided. The correct molecular weight should be $74 \mathrm{KD}$ and the name of reference gene should be $\operatorname{lamin} \mathrm{A} / \mathrm{C}$.
2. In Fig. 2a, on the western blot image of the R-HSC cells, the wrong reference gene "GAPDH" was listed, which is the same as $\alpha$-SMA.

3. In Fig. 2b, statistical analysis for the R-HSC cells was omitted.

4. In Fig. 2c, the incorrect image of HSC-T6 with $10 \mathrm{ng} / \mathrm{ml}$ HMGB1 was published, which is the same as NC.

5. In Fig. 3a, the wrong gene "GRP78" was listed, which is the same as IRE1 $\alpha$. The western blot of GRP78 is incorrect.

Please see correct figures (1-3) below.

The original article can be found online at https://doi.org/10.1038/ s41374-018-0085-9.

\footnotetext{
Dean Tian

datian@tjh.tjmu.edu.cn

yanwei@tjh.tjmu.edu.cn

1 Department of Gastroenterology, Tongji Hospital, Tongji Medical College, Huazhong University of Science and Technology,

Wuhan, China

2 Department of Gastroenterology, Union Hospital, Tongji Medical College, Huazhong University of Science and Technology,

Wuhan, China
}

$\triangle$ Wei Yan 


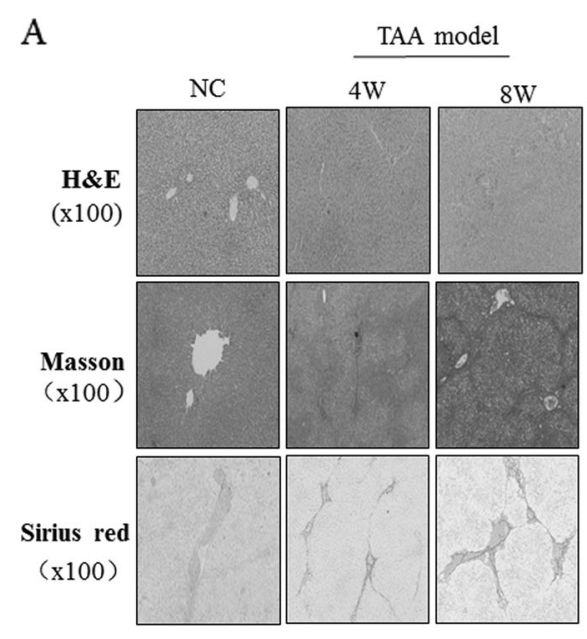
B

\begin{tabular}{|c|c|c|}
\hline & TAA model & \\
\hline KD & $\mathrm{NC} \quad 4 \mathrm{~W} \quad 8 \mathrm{~W}$ & \\
\hline 139 & - & Collagen-3 \\
\hline 129 & 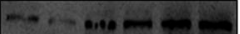 & collagen-1 \\
\hline 43 & -----0 & $\alpha$-SMA \\
\hline & - & GAPDH \\
\hline
\end{tabular}

C2 TAA model

KD $\mathrm{NC} 4 \mathrm{~W} 8 \mathrm{~W}$

$2900-600$ HMGB1-Nucleus

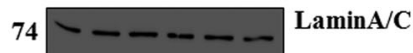

C1

\begin{tabular}{|c|c|c|c|c|c|c|c|}
\hline \multirow[b]{2}{*}{ KD } & \multicolumn{2}{|r|}{ TAA model } & & C3 & & TAA model & \\
\hline & $\mathrm{NC}$ & $4 \mathrm{~W} \quad 8 \mathrm{~W}$ & & KD & $\mathrm{NC}$ & $4 \mathrm{~W} 8 \mathrm{~W}$ & \\
\hline 29 & & $---\cdots$ & HMGB1-Total & 29 & & $-\cdots-$ & HMGB1-Cytoplasm \\
\hline 37 & & & GAPDH & 37 & $\infty$ & மாோ & GAPDH \\
\hline
\end{tabular}

D

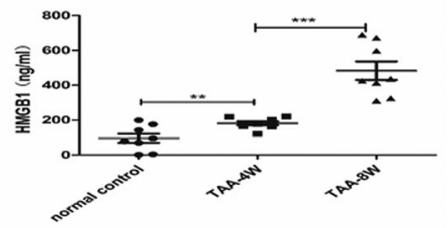

E

HMGB1

HMGB1 DAPI
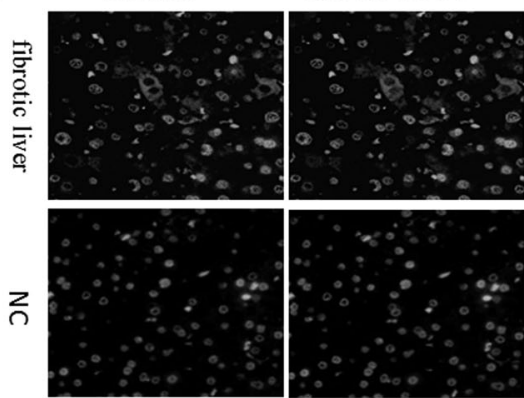

F

NC

TAA-4W
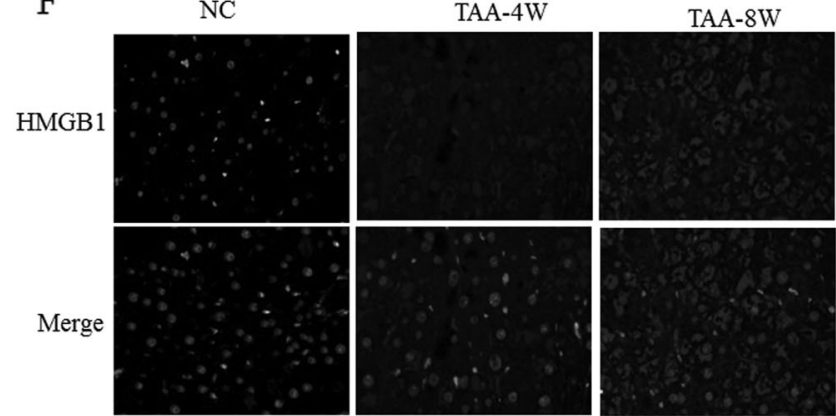

Fig. 1 
A

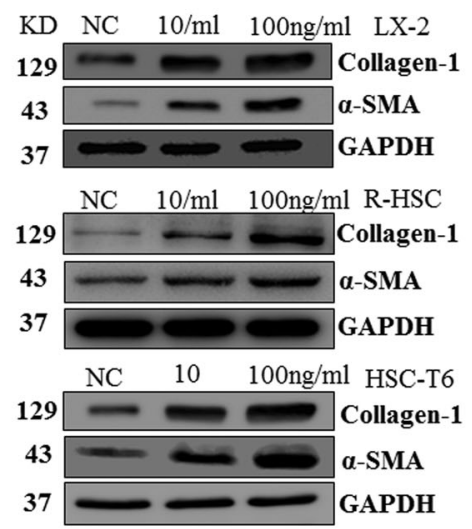

B

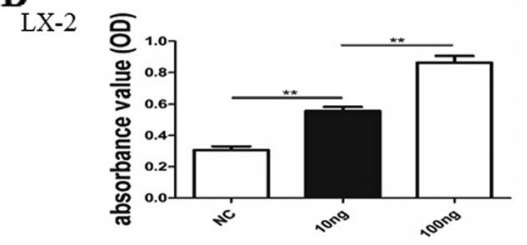

R-HSC

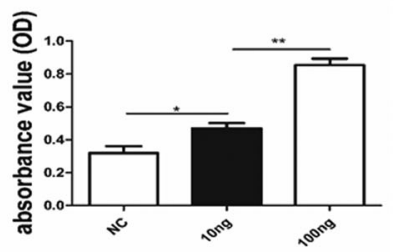

HSC-T6

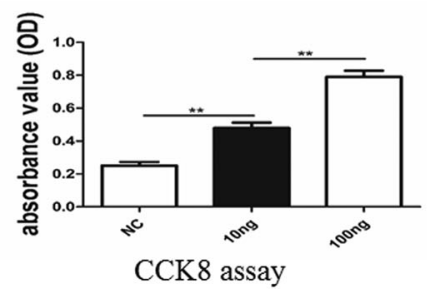

C
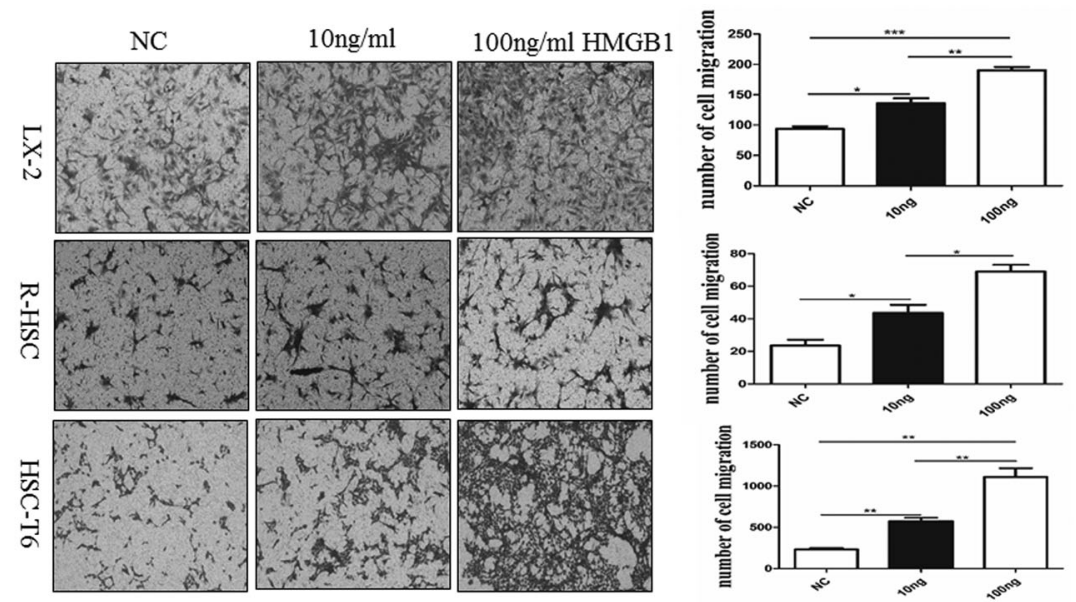

D
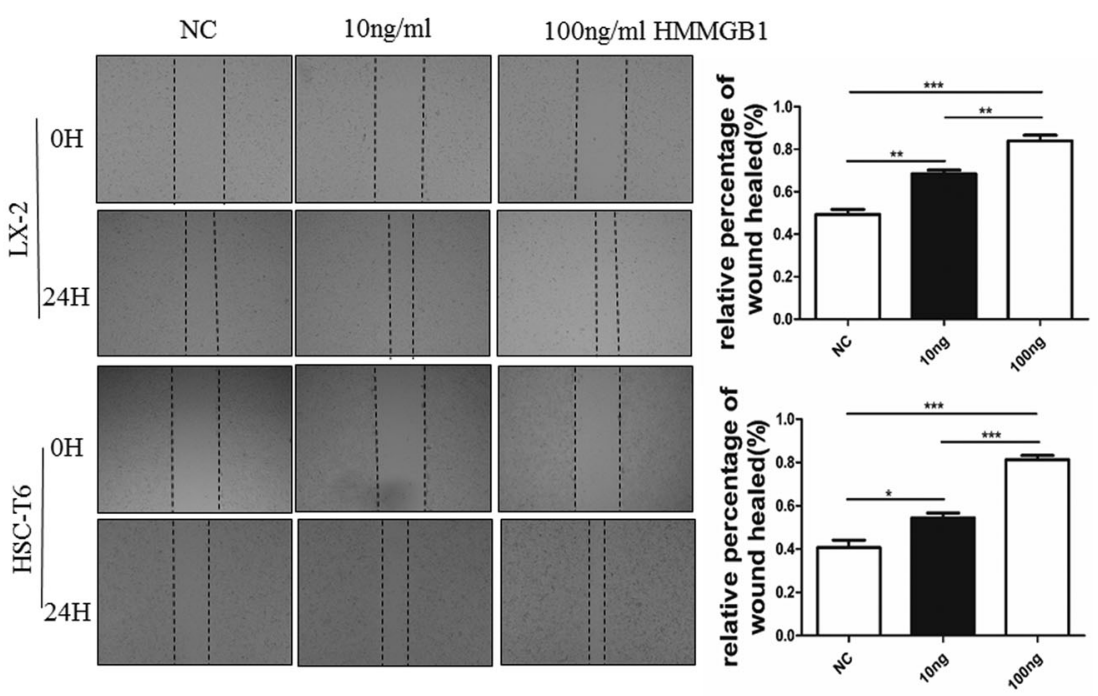

Fig. 2 


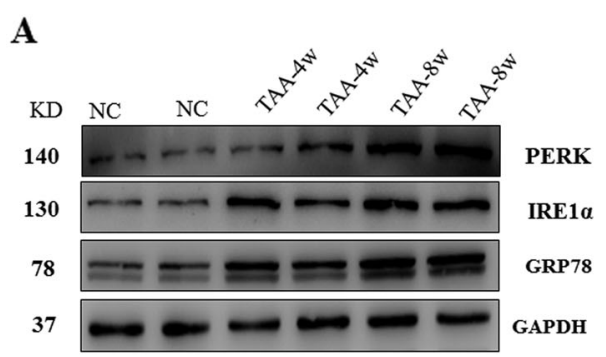

B

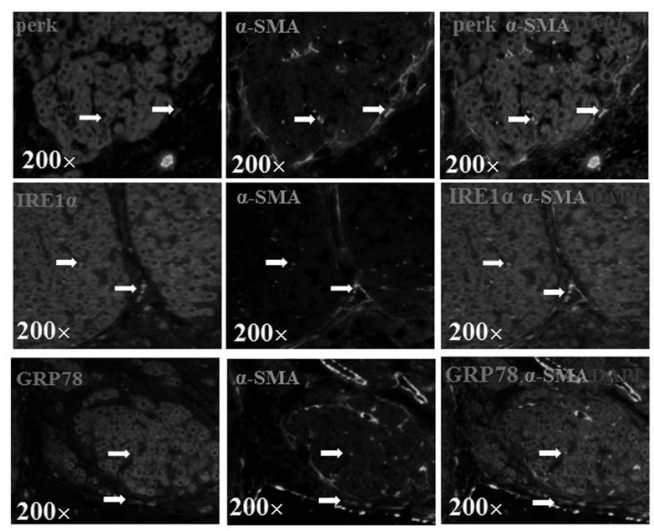

C
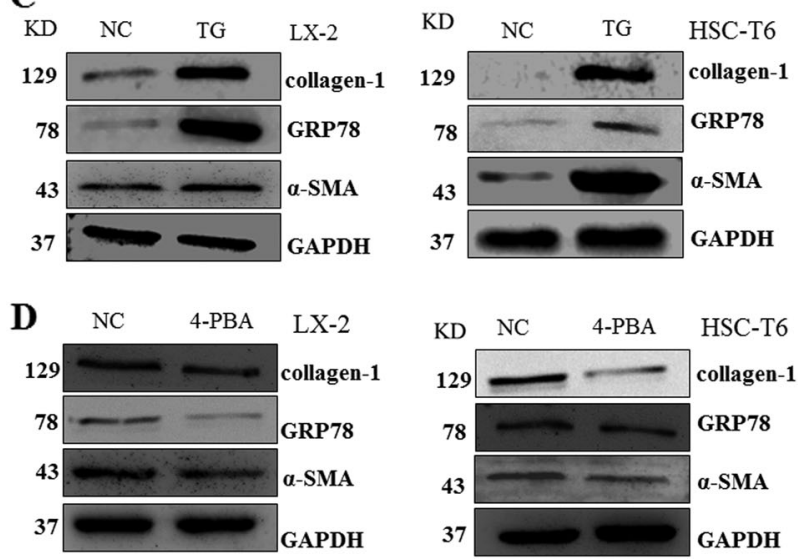

Fig. 3 